\title{
Política turística para el desarrollo sostenible del turismo cultural / San Juan de los Remedios, Cuba
}

DOI: 10.22403/UQROOMX/TYP03/04

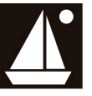

Manuel González Herrera*

\section{RESUMEN}

Este trabajo propone un programa de política turística sectorial para la ciudad San Juan de los Remedios, Cuba central, que se ha constituido en una nueva oferta de producto histórico-cultural. El programa se fundamenta en los principios de la sostenibilidad como modelo de desarrollo y se estructura en diez direcciones que presuponen la institucionalización de una política turística municipal y una estrategia para el desarrollo sostenible del turismo con participación de la comunidad local, la creación de una organización para la gestión turística municipal, la asignación de roles y responsabilidades a los diferentes gestores turísticos locales, la implementación de programas y planes de gestión integral del sistema turístico en la ciudad, y el fomento de proyectos de desarrollo. La implementación de las políticas formuladas permitirá minimizar los impactos adversos generados por el desarrollo turístico y potenciar el aprovechamiento de los atractivos turísticos de base local.

Palabras | San Juan de los Remedios, Cuba, impactos del turismo, política turística,

CLAVE turismo, sostenibilidad,

*Universidad Central de Las Villas / manglez@fce.uclv.cu 


\section{Introducción}

La década de los años noventa introdujo importantes cambios en la geopolítica mundial que han repercutido en las diferentes regiones y países. Cuba resintió una grave afectación en su economía; y en la búsqueda de soluciones, se han producido profundas transformaciones en la estructura económica productiva del país, que han cambiado las funciones tradicionales de muchos de sus espacios. Tal es el caso del nuevo escenario inducido por el turismo, actividad económica asumida como una alternativa. Se revaloran entonces, nuevos espacios litorales, urbanos y naturales, que requieren de programas de políticas turísticas específicas para proyectar su desarrollo.

Atendiendo a las consideraciones expuestas por R. Arcarons y J. Datzira (2004: 37-47), es difícil para los territorios turísticos desarrollar una política turística específica, independiente de otros tipos de actuaciones gubernamentales. Por tal razón, el programa de política turística que se propone está estrechamente vinculado con las políticas de otros programas de desarrollo económico y social declarados en el Programa Nacional de Medio Ambiente y Desarrollo de Cuba.

El Programa Nacional de Medio Ambiente y Desarrollo de Cuba (1995:4-5) constituye la adecuación cubana de la Agenda 21, aprobada en la Conferencia de Naciones Unidas sobre Medio Ambiente y Desarrollo, celebrada en Río de Janeiro en 1992. En este documento se identifican nueve programas de desarrollo, entre los cuales se encuentra el Programa Nacional de Desarrollo del Turismo. En tal sentido, encuentra puntos coincidentes con otras políticas sectoriales y la política integral de desarrollo que gestionan el partido y el gobierno local. De esta forma, se reconocen las relaciones entre las políticas horizontales, las políticas sectoriales y la política turística.

El Programa Nacional de Desarrollo del Turismo en Cuba tiene como premisa fundamental compatibilizar el desarrollo turístico con la conservación y uso sostenible de los recursos existentes en cada destino. Responde a un detallado ordenamiento territorial para cada polo turístico y establece los lineamientos de protección ambiental, dando prioridad al proceso de Evaluación de Impacto Ambiental de proyectos de desarrollo turístico; al respecto, la Estrategia Ambiental Nacional presentada por el Ministerio de Ciencia, Tecnología y Medio Ambiente (1997: 38-54) plantea los instrumentos para su implementación. 


\section{San Juan de los Remedios, su inserción como destino de turismo cultural}

La ciudad San Juan de los Remedios se localiza en la región central de Cuba, forma parte de la provincia de Villa Clara en su extremo noreste. Cuenta con 19000 habitantes y se clasifica como una ciudad pequeña, caracterizada por las actividades agrícolas y de servicios. Presenta una estructura urbana irregular con una retícula difusa. Dista $53 \mathrm{~km}$ de la ciudad de Santa Clara, capital de la referida provincia, en el eje de articulación entre ésta y el destino turístico de sol y playa Jardines del Rey, el cual se desarrolla en el área insular próxima.

Esta ciudad se caracteriza por su riqueza histórica. Farto, historiador de la ciudad, refiere que:

bajo el nombre de San Juan de los Remedios, su origen data de 1545, por lo que constituye la octava villa fundada en Cuba durante la colonización española, a pesar de haber sido el segundo asentamiento poblacional español, fundado el 3 de mayo de 1513 como un feudo particular con el nombre original de Santa Cruz de la Sabana de Vasco Porcallo de Figueroa, con casi 500 años ya de existencia [Farto, 2004].

Saqueada por corsarios y piratas, sufrió incendios y destrucción; fue reubicada, $y$ tiempo después vuelta a construir; fue adquiriendo importancia hasta su consolidación definitiva hacia 1800 , etapa en la que se construyen la mayoría de las casas y mansiones que se conservan en la actualidad. El conjunto colonial que atesora esta ciudad, junto al de Trinidad de Cuba, representa uno de los más valiosos de la nación.

En correspondencia con tan rica historia, San Juan de los Remedios conserva con gran esplendor un patrimonio tangible caracterizado por los estilos arquitectónicos barroco, neoclásico y ecléctico. En 1980 su centro urbano histórico se declara monumento nacional, del cual la plaza Martí representa la zona más atractiva de la ciudad, escenario en el que sobresale la iglesia San Juan Bautista, una de las más antiguas y bellas de Cuba. Otro atractivo lo constituye la cultura popular tradicional; las Parrandas Remedianas representan una de las celebraciones populares más tradicionales de Cuba.

La puesta en valor turístico del patrimonio de la ciudad está generando un producto turístico urbano patrimonial de carácter histórico cultural, que recientemente se abre a la comercialización en el mercado internacional. 


\section{Programa de política turística local para San Juan de los Remedios}

\section{Fundamentos básicos}

La propuesta del programa de política turística sectorial para San Juan de los Remedios se fundamenta en los principios de la sostenibilidad. En tal sentido, pretende posicionar el desarrollo sostenible como modelo que permite optimizar las interacciones naturaleza-sociedad. Este modelo de desarrollo procura la satisfacción de las necesidades de la sociedad; fomenta el crecimiento económico financiero dentro de límites ambientales, sociales y tecnológicos; propicia la participación social; estimula políticas demográficas adecuadas y contribuye a mejorar los niveles de calidad de vida. Por tal razón, el modelo de desarrollo sostenible del turismo al que aspiramos incorpora las dimensiones: ambiental, sociocultural, tecnológica y económico-financiera, con el mismo nivel de prioridad para la toma de decisiones y ejecución de acciones de desarrollo local.

Para este destino turístico en formación, el enfoque estratégico y funcional se basa en la visión de un modelo de turismo sostenible, que toma en consideración las características de los mercados de interés y el reconocimiento de los impactos sobre el ambiente natural y humano. Se trata de un modelo abierto y flexible de turismo que incorpora los siguientes criterios:

- Institucionalización de una política turística municipal estratégica para el desarrollo sostenible del turismo, con apoyo y participación de la comunidad local en el marco de la política nacional y provincial para el desarrollo turístico. Esta política turística toma en cuenta los objetivos finales y programáticos, así como su contribución al desarrollo regional. Considera los tipos de turistas que realmente se desea atraer y hacia qué segmento de mercado se orienta el producto que se pretende ofertar.

- Creación de una organización local para la gestión turística en el municipio con representación de los intereses públicos y privados. Entre sus múltiples funciones favorecerá las interacciones con el resto de las organizaciones político administrativas, sociales, económicas, ambientales, etc., representadas en el territorio, tanto gubernamental 
como no gubernamental y evaluará los recursos y medios para garantizar la gestión, en correspondencia con la vocación turística del municipio.

- Identificación, asignación de roles y responsabilidades a los diferentes gestores turísticos locales, atendiendo a las relaciones que se establecen entre los siguientes actores:

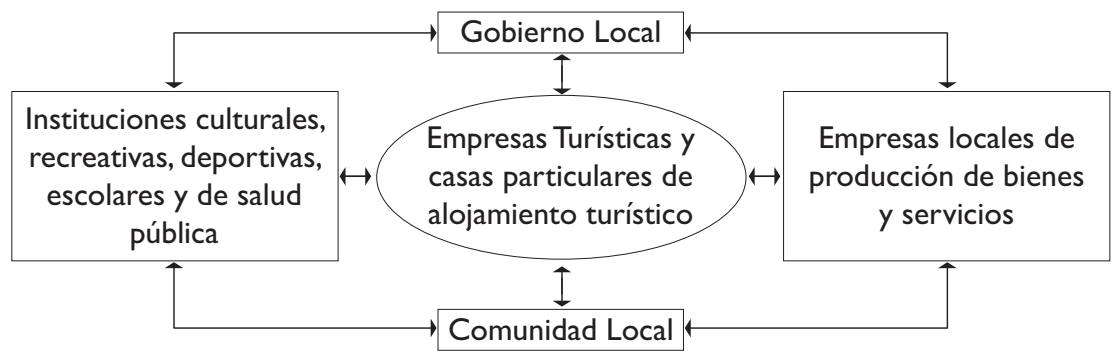

- Implementación de programas y planes de gestión integral del sistema turístico en la ciudad, así como el fomento de proyectos de desarrollo sobre bases sostenibles, en correspondencia con los programas y planes establecidos.

- Monitoreo y evaluación del desarrollo turístico atendiendo al modelo asumido para la gestión de los impactos del turismo en el nivel local.

\section{Políticas que integran el programa de desarrollo turístico sostenible del destino}

\section{Política de seguridad, protección y control del destino turístico}

Toma como premisa que la seguridad es una de las competencias distintivas del turismo en Cuba. Nuestra nación se ha posicionado en el mercado con la identidad de un país-destino atractivo por la garantía de su clima de paz, 
seguridad y protección al visitante, a partir de los altos niveles de estabilidad política y social que imperan. El desarrollo turístico local ofrece la garantía de una visita tranquila, alejada de situaciones de riesgo relacionadas con la violencia y el desorden público.

Es propósito de esta política: promover la actuación consciente de los gestores turísticos locales para mantener la seguridad y protección del destino en el contexto político y sociocultural del ordenamiento jurídico cubano; comprometer a los visitantes con comportamientos responsables alejados de manifestaciones que pongan en peligro su seguridad y la de los residentes; $y$ garantizar el control permanente de los niveles actuales de seguridad y protección al visitante y al residente.

\section{Política de planificación urbanística y ordenamiento turístico del destino}

Orienta la adecuación de usos y funciones a la aptitud del potencial funcional. En tal sentido, proyecta sobre bases sostenibles las nuevas obras y actividades, a la vez que el reordenamiento de las actividades incompatibles, con la función social actual del espacio. Toma en consideración que el desarrollo turístico de la ciudad ha heredado una planta urbana que no fue concebida para cumplir las exigentes funciones que el turismo impone a los espacios receptivos. Esto acrecienta la complejidad de las funciones de gestión del patrimonio urbano puesto en valor de uso turístico.

Es propósito de esta política: promover acciones de planificación física del espacio urbano orientadas al nuevo ordenamiento que requieren las zonas en uso turístico intensivo y el reordenamiento de las áreas deterioradas o de uso incompatible con la nueva función social; y conservar el ambiente físico urbano que soporta el emplazamiento de las actividades y la infraestructura de uso turístico, mejorando el aprovechamiento de las zonas funcionales de la ciudad, tanto para visitantes como para residentes.

\section{Política de marketing y comercialización turística del destino}

Pretende la atracción y mantenimiento creciente de los flujos turísticos internacionales y nacionales, respondiendo a la orientación hacia el cliente como base de la comercialización moderna. Se sustenta en la creación de una demanda efectiva de viajes, la satisfacción de los visitantes y el impacto sociocultural resultante de las interacciones entre los visitantes y la población 
local. El enfoque de mercado centra la atención en la plena satisfacción de los visitantes, a partir de la puesta en valor turístico de los atractivos patrimoniales de la ciudad, al tiempo que garantiza el cumplimiento del enfoque ético moral para la práctica de un turismo responsable de sana orientación, aprendizaje vivencial y protagonismo del destino.

Es propósito de esta política: promover una estrategia de atracción de los flujos turísticos enfocada a tipos y cantidad de clientes; alcanzar niveles satisfactorios de venta del producto turístico de ciudad, con precios que conlleven a un aumento de la eficiencia económica de las entidades e instituciones del destino; proyectar al mercado la identidad cultural de la ciudad patrimonial colonial cubana, para crear así un sello propio y exclusivo; y estudiar e incursionar en nuevos productos y mercados, lo que propiciará el incremento sostenido de los visitantes y una progresiva diversificación de las ofertas del destino.

\section{Política ambiental turística del destino}

Presupone compatibilizar las diferentes acciones inducidas por el turismo, tanto de carácter directo como indirecto y sus efectos para el ambiente local. Pretende la optimización de las situaciones ambientales relativas al turismo, en función de lo cual se trabaja para maximizar los efectos benéficos y minimizar los adversos que se producen para la salud, el bienestar y la seguridad humana. El alcance de esta dimensión se orienta al posicionamiento ambiental del destino sobre la base de un elevado confort ambiental, referido en términos de calidad ambiental.

Es propósito de esta política: implementar, como parte de la política integral de gestión del destino turístico, los principios básicos de la política ambiental cubana y de la legislación correspondiente; identificar, clasificar, evaluar y diseñar acciones de manejo para el control y monitoreo de los impactos ambientales generados por la localización y uso turístico del espacio con enfoque estratégico y operativo; actualizar la estrategia ambiental del sistema de turismo para la ciudad partiendo de la estrategia del territorio;y promover el reconocimiento ambiental de la gestión turística del destino.

\section{Políticas turísticas científica y tecnológica del destino}

Plantea estimular la actividad científica y tecnológica orientada a la producción de conocimientos que sustenten las estrategias y acciones del desarrollo turístico local. 
Es propósito de esta política: diseñar y desarrollar un programa local de ciencia e innovación tecnológica orientado a la optimización del uso turístico del espacio en correspondencia con el programa general del municipio; incrementar la cooperación provincial, nacional e internacional en trabajos conjuntos con los especialistas locales, para la búsqueda de soluciones integrales y multidisciplinarias enfocadas al fortalecimiento del conocimiento científico que sirva de base a las decisiones y a la innovación tecnológica; e incrementar la capacidad de asimilación relativa a la introducción de los resultados científicos y tecnológicos en función del desarrollo turístico.

\section{Políticas turísticas social y cultural del destino}

Propone mejorar la calidad de vida del residente y del turista durante su estancia en la ciudad y potenciar el desarrollo cultural de forma continua a partir de la puesta en valor de su patrimonio histórico, arquitectónico y folclórico.

Es propósito de esta política:asegurar que el desarrollo turístico contribuya a la calidad de vida local, valorada según estándares de bienestar de vida establecidos para el país y la percepción ciudadana del modelo de desarrollo del cual participan; favorecer la creación de empleo, generar ingresos y estimular el desarrollo regional mediante el turismo que genera la ciudad; conservar el patrimonio histórico, la cultura y la vida local para satisfacer las expectativas de los visitantes y las necesidades crecientes de los residentes bajo el concepto de mínimo impacto; y estimular otras formas de cultura contemporánea con el propósito de enriquecer la oferta del producto cultural y mejorar la calidad de vida de la población local, facilitando su accesibilidad al desarrollo cultural del destino.

\section{Política de calidad del destino turístico}

Plantea que todos los atractivos y las entidades turísticas y de apoyo actúen para la satisfacción de las expectativas y requerimientos de los clientes. Esta política se sutenta en la hospitalidad que nos caracteriza, considerando prioritarios la eficiencia y la eficacia de los procesos, la motivación y la formación contínua de los recursos humanos, el compromiso con los valores éticos, morales y culturales de nuestra sociedad y el cuidado del medioambiente, para potenciar la ciudad como destino turístico preferido en Cuba y en el Caribe.

Es propósito de esta política: disponer de un producto turístico de ciudad que satisfaga las expectativas y requerimientos de los clientes a través del 
establecimiento de un sistema de gestión de calidad que permita obtener una adecuada relación: calidad / precio; garantizar la satisfacción de los requisitos del cliente relacionados con la higiene, accesibilidad y seguridad del destino, mediante el cumplimiento de las regulaciones establecidas y los criterios valorativos resultantes de la percepción del visitante; mantener el equilibrio entre los componentes del producto turístico de la ciudad, atendiendo a la relación: calidad / capacidad de acogida; y establecer un sistema de control permanente a las diferentes operaciones y procesos de producción y servicios que tienen lugar en el destino, con el propósito de mantener su calidad.

\section{Política de formación, capacitación y concientización turística}

Plantea la contribución al desarrollo de una cultura turística ciudadana básica y especializada que permita la práctica de un turismo responsable en la doble dirección anfitrión-turista. Reconoce que la apreciación social por parte del habitante local del modelo de desarrollo que se inserta a su comunidad, y del cual debe ser protagonista, es esencial para el desarrollo sostenible, ya que si los residentes no aprecian los beneficios sociales y económicos que aporta el turismo, probablemente no estarán dispuestos a comprometerse como gestores turísticos.

Es propósito de esta política:favorecer el proceso de formación de la cultura turística básica de la población local, alcanzando elevados niveles de sensibilización sobre los beneficios sociales y económicos del turismo; buscar la participación de la sociedad local en el proceso de desarrollo turístico; y desarrollar programas de formación para los diferentes profesionales del sector turístico.

\section{Política interinstitucional y de gestión de la información turística}

Propone compulsar la gestión coordinada entre las diferentes instituciones y empresas turísticas que operan en la ciudad. Reconoce, como uno de los factores claves para el éxito del desarrollo integral del destino, los mecanismos establecidos para incentivar las relaciones entre las diferentes empresas del territorio y los esfuerzos dirigidos a promover el crecimiento del resto de las actividades y sectores económicos. Como base fundamental en la que se integran todos los gestores turísticos de la ciudad, se concede prioridad a la identificación, producción, procesamiento y gestión del sistema de información relativo al destino turístico. 
Es propósito de esta política: incentivar las relaciones empresariales locales y estimular el crecimiento de otros sectores vinculados directa e indirectamente a la actividad turística; potenciar la coordinación entre los diferentes actores con incidencia en la ciudad; $y$ promover la gestión de una página web de promoción turística para el destino.

\section{Política inversionista, económica y de financiación turística}

Propone completar una planta turística suficiente, un crecimiento económico endógeno y la diversificación de los mecanismos de financiación. Atendiendo a las características y proyección de desarrollo turístico de este destino, el proceso inversionista es limitado. Se trata de la reconversión de usos y funciones, mediante las cuales se ponen en valor inmuebles ya existentes, con un mínimo de recursos.

Es propósito de esta política: incentivar la atracción de inversiones en correspondencia con los principios establecidos en la Ley de Inversión Extranjera en Cuba; fomentar el crecimiento de la economía local con una importante contribución del sector turístico; y evaluar e implementar fuentes de financiación turística que favorezcan el proceso de desarrollo local fundamentado en criterios de mínimo impacto.

\section{Conclusiones}

La propuesta del programa de política turística local para la ciudad San Juan de los Remedios constituye un documento orientador que puede ser de valor utilitario para la gestión integrada del desarrollo turístico sostenible de este destino en formación. Su elaboración se sustenta en un detallado proceso de búsqueda de información y trabajo grupal, así como en un proceso inicial de conciliación con los gestores implicados.

Este programa de desarrollo turístico sostenible para el destino, en correspondencia con la gestión integrada de las diez líneas de políticas diseñadas, permitirá minimizar los impactos adversos generados por el desarrollo turístico y maximizar los benéficos a partir de la institucionalización de una política turística municipal y la formulación de una estrategia para el desarrollo sostenible del turismo bajo enfoques participativos. La misma estará apoyada por la creación de una organización local para la gestión turística municipal y la implementación 
de programas y planes de gestión integral del sistema turístico en la ciudad, el fomento de proyectos de desarrollo sobre bases sostenibles acorde con los programas y planes establecidos, así como el monitoreo y evaluación del desarrollo turístico, en correspondencia con el modelo asumido para la gestión de los impactos del turismo en el nivel local.

\section{FUENTES CONSULTADAS}

Arcarons, R. y J. Datzira (2004). Los destinos turísticos locales: Singularidad de la gestión. [en línea]. Universidad de Barcelona. Disponible en http:// www.cett.es

Burguet, R. (1995). Ley núm. 77 de la Inversión Extranjera en Cuba. Madrid: Sangova. Centro de Información, Divulgación y Educación Ambiental (1995). Programa Nacional de Medio Ambiente y Desarrollo. Adecuación cubana al documento Agenda 2 I. La Habana: CIDEA / WWF.

Farto, R. (2004). Historia local de la ciudad San Juan de los Remedios. Comunicación personal.

Gaceta Oficial de la República de Cuba (1997) Ley núm. 81 del Medio Ambiente. La Habana. II de julio de 1997, edición extraordinaria.

González, M. (1999). Fundamentos teóricos y metodológicos del proceso de evaluación de impactos a proyectos turísticos. Tesis de doctorado, La Habana: Universidad de la Habana / Facultad de Geografía.

Ministerio de Ciencia,Tecnología y Medio Ambiente (1997). Estrategia ambiental nacional. La Habana: Centro de Información de la Energía.

Ministerio de Economía y Planificación (1996). Metodología para la evaluación de estudios de factibilidad de las inversiones turísticas. La Habana:Dirección de Inversiones.

Programa Nacional de Medio Ambiente .... (1995) Programa Nacional de Medio Ambiente y Desarrollo de Cuba. La Habana: Ministerio de Ciencia, Tecnología y Medio Ambiente

World Tourism Organization. (1995).“Carta del Turismo Sostenible”. Ponencia presentada en la Conferencia Mundial delTurismo Sostenible, Lanzarote, Islas Canarias, España.

(1993). Sustainable tourism development: Guide for local planners.Tourism and the environment. Madrid: George Mc Intyre. 


\section{Nuevas aproximaciones a la investigación turística 26, 27 y 28 de junio de 2008}

\section{Temáticas}

Medioambiente, Sociedad, Economía y Negocios

\section{Características de las ponencias}

Título, resumen (máximo 300 palabras)

Contenido (máximo 5000 palabras)

Conclusiones, Literatura citada

\section{Fechas límite}

Recepción de ponencias in extenso: Marzo 30, 2008.

Notificación de dictamen: Abril 30, 2008.

\section{Cuota}

Ponente: $\$ 100$ USD (\$75.00 USD antes de Mayo 30. 2008).

Participantes: $\$ 50.00$ USD (\$35.00 USD antes de Mayo 30, 2008).

\section{Conferencistas invitados}

Dr. Gabor Vereczi. OMT

Dr. Salvador Gómez Nieves. U. de G.

Envío de documentos a: Mtro. Romano Segrado Líder del CAT

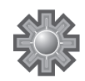

